\title{
Development of a home-based, comprehensive intervention program for family caregivers of dementia patients
}

\author{
Yoon Hee $\mathrm{Cho}^{1}$, Gwang Suk Kim², Hyun Jung Yun ${ }^{3}$, Jin Suk Ra ${ }^{* 4}$ \\ ${ }^{1}$ College of Nursing, Eulji University, Seongnam, South Korea \\ ${ }^{2}$ Nursing Policy Research Institute, College of Nursing, Yonsei University, Seoul, South Korea \\ ${ }^{3}$ Department of Nursing, Cheongju University, Cheongju, South Korea \\ ${ }^{4}$ College of Nursing, Chungnam National University, Daejeon, South Korea
}

Received: October 8, 2015

Accepted: December 10, 2015 Online Published: December 21, 2015

DOI: $10.5430 /$ jnep.v6n4p109

URL: http://dx.doi.org/10.5430/jnep.v6n4p109

\begin{abstract}
Objective: This study aims to develop a home-based and comprehensive education program for family caregivers who take care of the elderly with dementia at home.

Methods: The contents and approach methods of the preliminary program were developed by reviewing previous programs. The final program and intervention materials were determined by confirmation of the content validity by experts and clinical validity by caregivers of the elderly with dementia.

Results: The intervention contents selected for caregivers consisted of 6 concepts, 15 themes, and 37 items. The six main concepts were as follows: emotional support, knowledge improvement, skills training, self-care ability, communication, and use of resource. The program was scheduled for six weeks, and home visits, supportive phone-calls, and group meetings were offered to caregivers. Intervention materials included workbook, manuals, and charts.

Conclusions: An intensive and comprehensive intervention including diversified contents based on individual approaches should be utilized to decrease the negative experiences of caregivers who take care of the elderly with dementia.
\end{abstract}

Key Words: Family caregivers, Dementia, Program development, Written material

\section{INTRODUCTION}

The percentage of the elderly population is increasing every year because of an extended life expectancy and reduced fertility rate. Korea was defined as an aging society in 2000 , when people aged 65 and older exceeded $7 \%$ of the total population. Their total number is 5,193,000 and comprised approximately $10.7 \%$ of the total Korean population in a 2009 elderly survey; they are estimated to comprise approximately $14 \%$ of the total population in $2018 .^{[1,2]}$
It is difficult to know the exact number of people with senile dementia in Korea; however, in a nationwide study on the prevalence of dementia, dementia patients over the age of 65 were approximately $8.4 \%$ (total 421,387; men 163,451, women 257,936 ) of the population. ${ }^{[3]}$ That same study reported that the number of dementia patients will increase 2 times every 20 years due to rapid ageing. This issue is expected to emerge as a significant problem for Korean society in the future. ${ }^{[4]}$

\footnotetext{
*Correspondence: Jin Suk Ra; Email: jinsukra@ cnu.ac.kr; Address: College of Nursing, Chungnam National University, Jung-gu, Munhwa-ro 266, Daejeon, South Korea.
}

Published by Sciedu Press 
Many dementia patients need help from other people. In most cases, patients' family members take care of them in Korea because of cultural characteristics, such as family obligation $^{[4]}$ so dementia is one of the stressors affecting the whole family. People with dementia live, on average, 7 to 10 years after diagnosis, and most of those years are spent at home. ${ }^{[5]}$ Accordingly, family members spend a lot of time with them, taking care of them. Caring for a person with dementia is a difficult and often overwhelming task and more and more people are facing this challenge. ${ }^{[5]}$ Therefore, both the people with dementia and their family members should be considered as part of the nursing client.

Chenweth and Spencer said that family cohesion and the self-esteem of the primary caregiver increased when family members were well adapted to the stressors caused by dementia patients. ${ }^{[6]}$ However, most researchers mentioned that the family experienced more negative changes than positive changes, ${ }^{[7]}$ and the negative outcomes experienced by family members living with people with dementia can appear both psychologically and physically. Generally, negative experiences were as follows: depressive disorder, ${ }^{[8-10]}$ anxiety disorder, ${ }^{[9-11]}$ lower levels of life satisfaction, ${ }^{[12]}$ burden, ${ }^{[9,10,13,14]}$ loss of self, ${ }^{[15]}$ prolonged distress, ${ }^{[15]}$ emotional strain, ${ }^{[16]}$ family conflict, ${ }^{[17,18]}$ decreased quality of life, ${ }^{[19]}$ decrease in preventive health behaviors, ${ }^{[18]}$ decrements in immunity measures, ${ }^{[11,20]}$ fatigue,${ }^{[21]}$ and a worsening of headaches, insomnia, and digestive symptoms. ${ }^{[22]}$ That is to say, many family caregivers, especially caregivers at home without the help of experts, experience suffering and difficulty while taking care of the elderly with dementia. Accordingly, family caregivers need professional help.

In recent years, researchers have done an increasing number of clinical trials for family caregivers of the elderly with dementia in order to reduce their difficulties and to help them. ${ }^{[23]}$ Previous studies on interventions for caregivers generally used programs, which consisted of a singlecomponent or a few components such as emotional and educational support, and stress management. However, Schultz and Martire described that interventions combining various contents and different strategies were more effective than single-component interventions in a study on "Stress/Health model" applied to caregiving \& associated intervention. ${ }^{[15]}$ In addition, the intervention approach in previous studies was usually in the form of group meetings or sessions. ${ }^{[24-26]}$ However, most caregivers taking care of the elderly with dementia without professional help at home cannot participate in group meetings or sessions unless other people look after the patient. In other words, a community or home-based approach is needed. ${ }^{[27]}$
Therefore, the aim of this study was to develop a home-based and comprehensive intervention program for family caregivers who take care of the elderly with dementia at home.

\section{Methods}

\subsection{Research design}

This study was on developing a program for family caregivers who take care of the elderly with dementia at home.

\subsection{Research procedures}

The program development stages are as follows and presented in Figure 1. The program was developed on the basis of the phase of ADDIE (Analysis, Design, Development, Implementation, Evaluation) by Seels \& Richey. ${ }^{[28]}$

\subsubsection{Determine the needs of the family caregiver and con- tents and strategies of previous programs through a literature review}

The needs of family caregivers were determined by a literature review in order to develop specific contents for the intervention. Cho noticed the highest need of family caregivers consisted of 4 sub-dimensions (knowledge of dementia and dementia patients' management, skills for caring for dementia patients, services for family caregivers, and community resources connection); ${ }^{[29]}$ therefore, 17 items with the highest demand within the 4 sub-dimensions were included in this study. To determine more appropriate intervention contents and strategies, previous research was reviewed. CINAHL, MEDLINE, KISS, and RISS, free search engines for accessing databases, were used to search for articles on related topics. A total of 51 international articles and 20 Korean articles (including master's theses and Ph.D. dissertations since there were only a few related articles) were retrieved from the four search engines using the following terms: dementia and caregiver; dementia and family; Alzheimer and caregiver; and Alzheimer and family. At the same time, three conditions, namely, clinical trial (type of article), and English (language), were attached as limit conditions when the articles were retrieved on CINAHL and MEDLINE. In addition, two conditions, namely, clinical trial (type of article) and Korean (language) were added on KISS and RISS. However, caregivers who took care of Huntington disease patients were excluded because dementia patients caused by that disease are rare in Korea. Finally, 18 articles fit the above search criteria and, accordingly, were analyzed.

\subsubsection{Development of the preliminary protocol}

A preliminary protocol for the intervention included a workbook, manuals, and charts. The workbook-containing educational contents based on the six sub-concepts of intervention selected through a literature review-was developed on the basis of the needs of the family caregivers (see Table 1). 
Manuals and charts were also developed preliminarily for nursing activities.

\subsubsection{Confirmation of content validity by experts}

For content validity, expert review and round-table discussion were used. The expert group consisted of three professors (two professors of geriatric nursing and one professor of community health nursing), three geriatric nurse practitioners (having extensive experience with the care of elderly patients in communities and institutions), and two dementia nurses (having three or more years of experience in local dementia centers). These eight experts were engaged in re- viewing the two components of the intervention for content validity as outlined by Lynn: ${ }^{[30]}$ the relevance of program contents and adequacy of the materials. Each item had a 4-point rating scale and asked experts to respond to each question by checking "strongly agree", "agree", "disagree", or "strongly disagree" and computed a content validity index (CVI) according to the recommendations of Lynn. ${ }^{[30]}$

After expert review, this researcher and three professors conducted a round-table discussion and determined intervention contents and protocols on the basis of CVI scores and expert opinions through expert review.

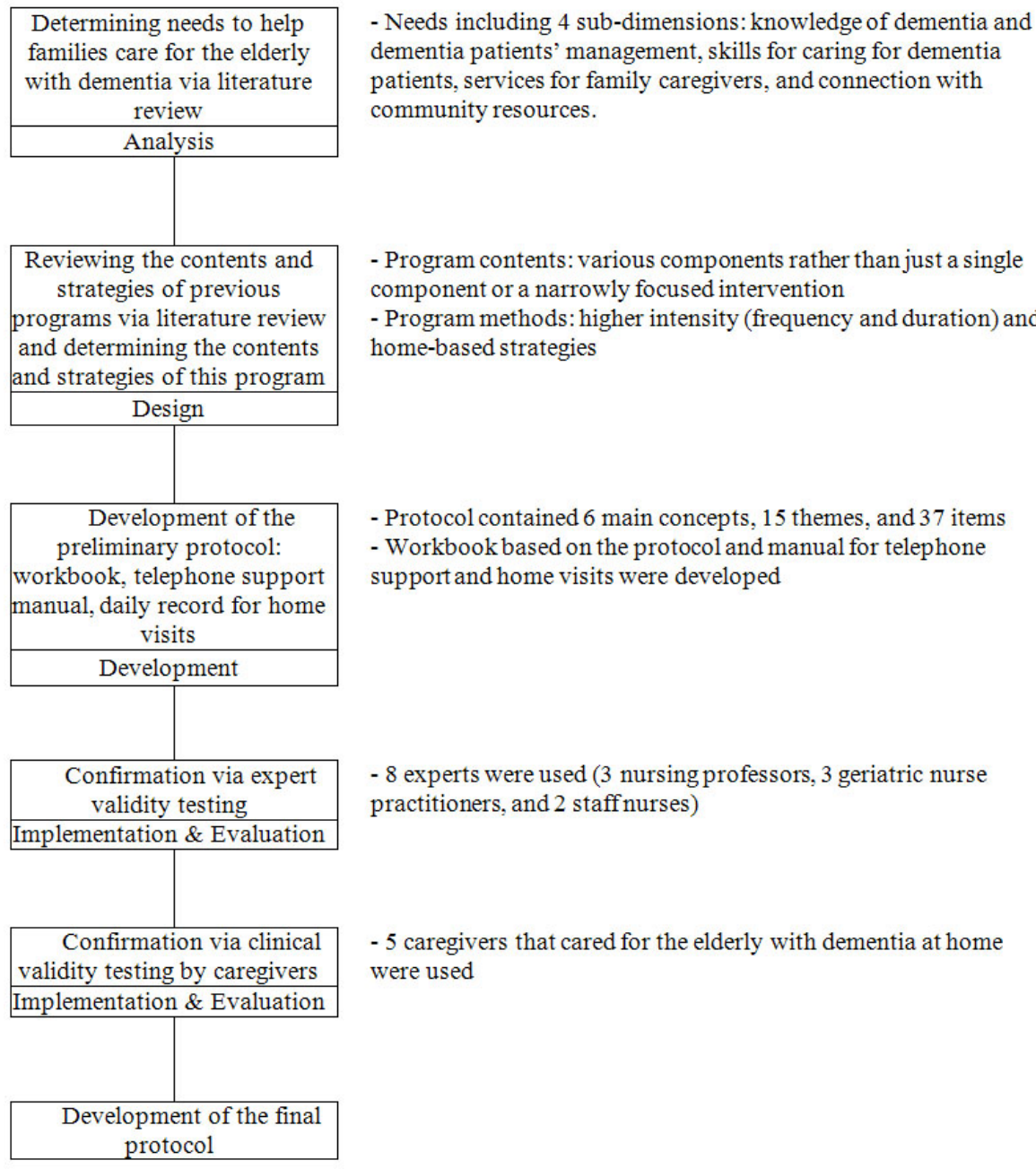

Figure 1. Program development stages

\subsubsection{Confirmation of clinical validity by caregivers of the elderly with dementia}

After the test for content validity, clinical validity was tested by users in order to examine whether developed workbook was useful for family caregivers of dementia patients. For clinical validity, this researcher interviewed five caregivers. Caregivers were asked to review three components of the intervention: the necessity of the contents, the adequacy of the representation, and the ease of understanding.

\subsubsection{Development of the final protocol}

After reviewing the feedback from both the experts and caregivers, the intervention protocol was revised. The workbook, manuals, and charts were then modified using the revised protocol. 
Table 1. The results of the validity test and contents of the program

\begin{tabular}{|c|c|c|c|c|c|c|c|}
\hline \multirow[b]{2}{*}{$\begin{array}{l}\text { Main } \\
\text { concept }\end{array}$} & \multirow[b]{2}{*}{ Themes } & \multirow[b]{2}{*}{ Item } & \multicolumn{2}{|c|}{$\begin{array}{l}\text { Results of the expert } \\
\text { validity test }\end{array}$} & \multicolumn{3}{|c|}{ Results of the clinical validity test } \\
\hline & & & $\begin{array}{l}\text { Relevance } \\
\text { of program } \\
\text { contents }\end{array}$ & $\begin{array}{l}\text { Adequacy } \\
\text { of } \\
\text { materials }\end{array}$ & $\begin{array}{l}\text { Necessity } \\
\text { of con- } \\
\text { tents }\end{array}$ & $\begin{array}{l}\text { Adequacy of } \\
\text { represent- } \\
\text { tation }\end{array}$ & $\begin{array}{l}\text { Ease of } \\
\text { under- } \\
\text { standing }\end{array}$ \\
\hline \multirow{4}{*}{$\begin{array}{l}\text { Emotional } \\
\text { support }\end{array}$} & \multirow{4}{*}{ Emotional support } & $\begin{array}{l}\text { Psychological support between } \\
\text { caregivers }\end{array}$ & 1.00 & 1.00 & 1.00 & 1.00 & 1.00 \\
\hline & & Encouragement of free self-expression & 1.00 & 1.00 & 1.00 & 1.00 & 1.00 \\
\hline & & Support by experts & 1.00 & 1.00 & 1.00 & 1.00 & 1.00 \\
\hline & & $\begin{array}{l}\text { Maintaining changed behaviors after } \\
\text { application of the program }\end{array}$ & 1.00 & 1.00 & 1.00 & 1.00 & 1.00 \\
\hline \multirow{5}{*}{$\begin{array}{l}\text { Knowledge } \\
\text { improve- } \\
\text { ment }\end{array}$} & \multirow{3}{*}{ Basic information } & Definition of dementia & 1.00 & 1.00 & 1.00 & 1.00 & 1.00 \\
\hline & & Cause of dementia & 1.00 & 1.00 & 0.80 & 1.00 & 1.00 \\
\hline & & Symptoms and progress of dementia & 1.00 & 1.00 & 1.00 & 1.00 & 1.00 \\
\hline & Treatment and & Medication & 1.00 & 0.75 & 0.80 & 1.00 & 1.00 \\
\hline & management & General management and caring & 1.00 & 1.00 & 0.80 & 1.00 & 1.00 \\
\hline \multirow{5}{*}{$\begin{array}{l}\text { Skill } \\
\text { training }\end{array}$} & $\begin{array}{l}\text { Impaired memory } \\
\text { management }\end{array}$ & $\begin{array}{l}\text { Strategies and skills to manage impaired } \\
\text { memory }\end{array}$ & 1.00 & 1.00 & 1.00 & 1.00 & 1.00 \\
\hline & $\begin{array}{l}\text { Psychiatric } \\
\text { symptoms } \\
\text { management }\end{array}$ & $\begin{array}{l}\text { Strategies and skills to manage } \\
\text { psychiatric symptoms }\end{array}$ & 1.00 & 1.00 & 1.00 & 1.00 & 1.00 \\
\hline & $\begin{array}{l}\text { Behavioral } \\
\text { problems } \\
\text { management }\end{array}$ & $\begin{array}{l}\text { Strategies and skills to manage } \\
\text { behavioral problems }\end{array}$ & 1.00 & 1.00 & 1.00 & 1.00 & 1.00 \\
\hline & Care of ADL & Eating, Dressing, Toileting, Bathing & 1.00 & 1.00 & 1.00 & 1.00 & 1.00 \\
\hline & $\begin{array}{l}\text { Environmental } \\
\text { management }\end{array}$ & $\begin{array}{l}\text { Environment management for the safety } \\
\text { of the elderly with dementia }\end{array}$ & 1.00 & 0.75 & 1.00 & 1.00 & 1.00 \\
\hline \multirow{5}{*}{$\begin{array}{l}\text { Communi- } \\
\text { cation }\end{array}$} & $\begin{array}{l}\text { Adaptation of } \\
\text { family }\end{array}$ & Adaptation stage of the family & 0.88 & 1.00 & 1.00 & 1.00 & 1.00 \\
\hline & \multirow{2}{*}{$\begin{array}{l}\text { Positive } \\
\text { relationships with } \\
\text { the elderly with } \\
\text { dementia }\end{array}$} & $\begin{array}{l}\text { Attitude towards the elderly with } \\
\text { dementia }\end{array}$ & 1.00 & 0.86 & 1.00 & 1.00 & 1.00 \\
\hline & & $\begin{array}{l}\text { Communication with the elderly with } \\
\text { dementia }\end{array}$ & 1.00 & 1.00 & 1.00 & 1.00 & 1.00 \\
\hline & \multirow{2}{*}{$\begin{array}{l}\text { Communication } \\
\text { between family } \\
\text { members }\end{array}$} & $\begin{array}{l}\text { Communication between family } \\
\text { members }\end{array}$ & 1.00 & 1.00 & 1.00 & 1.00 & 1.00 \\
\hline & & Sharing roles between family members & 1.00 & 1.00 & 1.00 & 1.00 & 1.00 \\
\hline \multirow{8}{*}{$\begin{array}{l}\text { Self-care } \\
\text { ability }\end{array}$} & \multirow{5}{*}{ Stress management } & Experience feelings of family caregivers & 1.00 & 1.00 & 1.00 & 1.00 & 1.00 \\
\hline & & Life management of family caregivers & 1.00 & 1.00 & 1.00 & 1.00 & 1.00 \\
\hline & & Stress management of family caregivers & 1.00 & 1.00 & 1.00 & 1.00 & 1.00 \\
\hline & & $\begin{array}{l}\text { Strategy for stress management } \\
\text { 1: Relaxation }\end{array}$ & 1.00 & 1.00 & 1.00 & 1.00 & 1.00 \\
\hline & & $\begin{array}{l}\text { Strategy for stress management } \\
\text { 2: Massage }\end{array}$ & 1.00 & 1.00 & 1.00 & 1.00 & 1.00 \\
\hline & \multirow{3}{*}{$\begin{array}{l}\text { Maintaining } \\
\text { physical health }\end{array}$} & Nutrition for family caregivers & 0.75 & 1.00 & 1.00 & 1.00 & 1.00 \\
\hline & & Physical activities for family caregivers & 0.75 & 1.00 & 1.00 & 1.00 & 1.00 \\
\hline & & $\begin{array}{l}\text { Preventive health behaviors for family } \\
\text { caregivers }\end{array}$ & 1.00 & 0.88 & 1.00 & 1.00 & 1.00 \\
\hline \multirow{10}{*}{$\begin{array}{l}\text { Use of } \\
\text { resource }\end{array}$} & \multirow{8}{*}{ Available services } & Elderly long-term care insurance system & 1.00 & 1.00 & 1.00 & 1.00 & 1.00 \\
\hline & & Daycare center & 1.00 & 1.00 & 0.40 & 0.60 & 0.60 \\
\hline & & Short-term elderly care facilities & 1.00 & 1.00 & 1.00 & 1.00 & 1.00 \\
\hline & & Long-Term care facilities & 1.00 & 1.00 & 1.00 & 1.00 & 1.00 \\
\hline & & Visit bath services & 0.75 & 1.00 & 1.00 & 1.00 & 1.00 \\
\hline & & Dementia support center & 1.00 & 1.00 & 1.00 & 1.00 & 1.00 \\
\hline & & Service for report of disappearance & 1.00 & 1.00 & 1.00 & 1.00 & 1.00 \\
\hline & & $\begin{array}{l}\text { Contact address of available services } \\
\text { within locality }\end{array}$ & 1.00 & 1.00 & 1.00 & 1.00 & 1.00 \\
\hline & \multirow{2}{*}{$\begin{array}{l}\text { Available program } \\
\text { to gain information }\end{array}$} & Internet address to get help & 1.00 & 1.00 & 1.00 & 1.00 & 1.00 \\
\hline & & Book to get help & 1.00 & 1.00 & 1.00 & 1.00 & 1.00 \\
\hline
\end{tabular}




\subsection{Ethical considerations}

The study was approved by the Institutional Review Board of the Y University College of Nursing in Korea. Informed consent was obtained from all participants after explaining the aims, process, and methods of this study.

\section{RESUlts}

\subsection{Selection of the contents and strategies of the pro- gram}

Main intervention contents selected for caregivers consisted of six concepts, 15 themes, and 37 items. The six main concepts were as follows: emotional support, knowledge improvement, skills training, self-care ability, communication, and use of resources. It was also decided to use higher intensity (frequency) and home-based strategies utilizing group meetings, telephone calls, and home visits.

\subsection{Development of the preliminary protocol: work- book, manuals, and charts}

To provide standardized services for caregivers, a workbook, manuals, and semi-structured nursing record for home visits and telephone calls were developed preliminarily based on the six concepts. The workbook included essential information and performance tasks for caregivers and the manuals guided interventions and education by nurses.

\subsection{Confirmation of the preliminary protocol: expert va- lidity and clinical validity}

The result of CVI by experts and caregivers is presented in Table 1 . The minimum agreement standard by the eight experts was more than $0.75 .^{[30]}$

The CVI scores for both the "relevance of program contents" and "adequacy of materials" were more than 0.75 for the test given to the experts. However, experts had some advice for parts of the materials. The comments were summarized as follows: uniformity of the terminology and some additional information on items. After reviewing the materials and a panel discussion on it, the material was revised, and the clinical validity test was carried out. In the clinical validity test determined by the caregivers, the scores for necessity, adequacy of representation, and ease of understanding in a daycare center were below 0.75 .

In this study, caregivers were caring for the elderly with dementia at home. However, the information from the daycare center was maintained in the final protocol based on the experts' advice.

\subsection{Development of the final protocol}

After review by the experts and caregivers, the intervention protocol was revised. The revised protocol contained 6 main concepts, 15 themes, and 37 items. Workbook, manuals, and charts (including semi-structured nursing record) were modified based on the revised protocol.

The workbook had Q \& As or a checklist inserted for every main concept, in order to enhance the participation of the caregivers. Charts were prepared for every caregiver and patient to maintain the continuity of care.

The program was scheduled for six weeks. Group meetings were held in the first and last week and home visits were conducted once a week from the second to fifth weeks. And telephone support was implemented every week.

\subsection{Preliminary application of the program}

The developed program was offered to five caregivers to ascertain its applicability. Nurses provided the education contents of the main theme at every home visit and group meetings for six weeks, but also applied them with flexibility depending on the knowledge level of the caregivers as well as the condition of the elderly with dementia. Nurses also provided emotional support, reinforced previous education and behavioral changes, and were assigned tasks to do until the next home visit or phone call.

The actual intervention was done by nurses each time, which included the following: 90 minutes to two hours of home visits; telephone call five to ten minutes, and caregivers group meetings for 90 minutes, respectively. Home visits and telephone calls were applied individually. In addition, assistants accompanied the nurses to the home visits to provide care for the elderly with dementia during the participation of caregivers in the program as required on occasion. However, some caregivers did not participate in the group meetings of caregivers because there was no family member to take care of the elderly on behalf of them or they refused to do so for personal reasons (i.e., too busy and did not want others to know).

The satisfaction assessment was conducted after completing the program. The results are summarized in Table 2 . The program satisfaction scale consists of six items, ranged from one (not at all) to 4 (very satisfactory), the average scores of six items were all above than 3 points. The highest score items were the satisfaction nurse and materials (workbook and goods provided during the program).

\section{Discussion}

A caring for a family member with dementia is one of the stressors that affect the whole family. Most people live with chronic conditions such as dementia and most elderly people are supported by family members, ${ }^{[31]}$ and family members spend a lot of time with the elderly to take care of them. 
Thus, family members are required to learn new information and practices for care. For that reason, Schults and Martire suggested that interventions combining different strategies and providing caregivers with diverse services and support tend to generate larger effects than narrowly-focused interventions. ${ }^{[15]}$ Therefore, in this study, various contents and approach methods were adopted simultaneously depending on the needs of the caregivers.

Table 2. Evaluation of participants' program satisfaction

\begin{tabular}{llll}
\hline Variables & M & SD & Range \\
\hline Could get information about how to care for the elderly with dementia & 3.8 & 0.45 & $3-4$ \\
Could learn skills about how to care for the elderly with dementia & 3.6 & 0.55 & $3-4$ \\
Could have confidence in caring for the elderly with dementia & 3.2 & 0.87 & $2-4$ \\
Be satisfied with the nurse who has provide the program & 4.0 & 0 & 4 \\
Could contact a nurse as needed & 3.6 & 0.55 & $3-4$ \\
Be satisfied with the materials provided during the program & 4.0 & 0 & 4 \\
\hline
\end{tabular}

The intervention contents were applied with flexibility depending on the conditions of the caregivers and the available intervention items were varied for each caregiver. These facts are in agreement with the opinions of previous researchers such as Cho who described that health care providers should have provided practical help to caregivers, based on those diversified needs. ${ }^{[29]}$ Kennet, Burgio, and Schulz also suggested a comprehensive, intensive, and individually tailored intervention to increase effectiveness. ${ }^{[23]}$ Actually, recent studies also tend to provide interventions, which have included diversified service contents or supports. ${ }^{[27,32,33]}$

The program developed in this study included skill training as well as knowledge improvement. Kennet, Burgio, \& Schulz mentioned that if the informative needs have been met, the caregivers might additionally desire more training on general problem solving skills as well as more specific skills in areas such as managing the patients' behaviors. ${ }^{[23]}$ Thus, it is likely that caregivers desire to learn more specific information that applies to their needs and specific situation rather than general information. Yoo and Ha reported that information about how to care was the biggest need. ${ }^{[34]}$ In addition, Cho reported that the second largest need of caregivers was the skill to care for patients with dementia. ${ }^{[29]}$ Thus, skill training was considered as an important part of this program. Namely, skill training by a nurse was provided depending on the situation of the caregivers at home after nurses checked for symptoms and ADLs of the elderly with dementia as well as for the environmental safety conditions of the resident.

Communication in this study included how to build a positive relationship as well as verbal communication with the elderly with dementia and other family members. Many caregivers in Korea experience distress due to unfair and heavy responsibilities; therefore, this sometimes causes a conflict in the family, and they wish to improve difficult situations including large and small family conflicts. ${ }^{[4,35]}$ Accordingly, this program included communication skills among family members and how to share roles in addition to the aforementioned intervention contents. These intervention contents are expected to be effective as family coping strategies and for providing comfortable situations.

Schulz and Martire explained that caregivers experienced not only psychological problems, but also physical health problems. ${ }^{[15]}$ It is believed that psychological conditions, such as strain or stress in caregivers, affect their physical health. In addition, caregivers also tend to lessen their own health or experience physical fatigue because they spend most of their time at home caring for the elderly with dementia. ${ }^{[36]}$ Thus, not only psychological symptoms, such as stress, but also physical health were included in the program. Namely, this program focused on caregivers' individual health as well as caregivers' abilities to care for the elderly with dementia. However, caregivers do not tend to respond to or identify with the need to care for themselves until they experience declining health of their own. ${ }^{[37]}$ Accordingly, health care providers had to develop specific strategies and methods to change caregivers' bad habits or to learn how to improve caregivers' psychological and physical health before they experience bad health. In addition, health care providers need to emphasize that caregivers' health can affect the conditions of the elderly and the wellness of the whole family.

Practical information about the use of resources, such as the contact address of available local services or how to obtain insurance service, was one of the most sought after help for caregivers. ${ }^{[38]}$ Cho also reported that "community resources networking" was the highest need of caregivers. ${ }^{[29]}$ Therefore, health care providers need to establish an integrated information center that can guide the programs and contents 
for families of patients with dementia and have to actively advertise the center.

As a result of applying the program to five family caregivers who take care of dementia patients for six weeks, family caregivers were satisfied with the program generally. In particular, family caregivers were most satisfied with materials and nurses. However, family caregivers did not have confidence in caring for the dementia patients relatively. Therefore, additional considerations for confidence improvement of caregivers were required.

Most interventions developed in Korea adopted a group session. ${ }^{[26,39,40]}$ It is difficult for caregivers who care for the elderly at home to participate in a group program unless someone else takes care of the elderly person during the group session. ${ }^{[41-43]}$ Actually, three of the five caregivers who applied to this program did not attend the group meetings. Accordingly, complementary ways should be considered to promote actual participation, or other approach methods need to be selected instead of a group program.

\section{Practice implications}

In Korea, a number of the elderly with dementia in the community sector are taken care of by their family members at home because of family obligations. Caring for the elderly without professional helps requires much time and effort from caregivers due to the nature of the disease. Thus, many caregivers often experience providing care as a difficult and overwhelming task; therefore, programs for caregivers need to be developed on the basis of their needs to reduce their negative experiences and help them from becoming exhausted. Especially, an intensive and comprehensive intervention including diversified contents based on individual approaches should be utilized in order to maximize the effectiveness of the intervention.

\section{Conclusion}

The aim of this study was to develop a more appropriate program than that of existing programs for family caregivers who provide care to the elderly with dementia at home in Korea. As a result, a home-based, comprehensive intervention program was developed through related literature review, validity testing, and preliminary application of the program. The program for family caregivers included 6 main concepts, 15 themes with 37 items. The six concepts were as follows: 1) emotional support, 2) knowledge improvement, 3) skills training, 4) self-care ability, 5) communication, and 6) use of resources. In addition, workbook, manuals, and semistructured charts were developed. The period for the program implementation was six weeks including home visits, group meetings, and supportive phone calls.

However, this study has a limitation. The effectiveness of the program was not tested using the experimental research design. Thus, further studies are needed to confirm the effectiveness of developed program through the conduct of adequate and wee-controlled trials. In addition, specific strategies to promote caregivers' attendance at group meetings have to be considered.

\section{ACKNOWLEDGEMENTS}

We would like to thank the patients who participated in this study. This work was supported by Yonsei University College of Nursing of 2010.

\section{CONFlicts OF InTEREST Disclosure}

The authors declare that they have no conflict of interest.

\section{REFERENCES}

[1] Statistics Korea (KOSTAT). 2009. Elderly statistics. Available from: http://www.kostat.go.kr/board_notice/BoardAct ion.do?method=view\&board_id=78\&seq $=666 \&$ num $=666 \&$ par ent_num=0\&page $=1 \&$ page_name $=a l l \_l i s t \& k i n d \_i d=2 \& c a t g r$ $\mathrm{p}=$ nso2009\&catid $1=\mathrm{k} 04$ _-_0000\&catid2 $=\mathrm{k} 04 \mathrm{~b}$ id3=\&catid4=

[2] Ministry for health, welfare and family affairs, National health insurance corporation. The status of long-term care institutions in 2008. Available from: http://www. longtermcare.or.kr/portal/si te/nydev/menuitem.7a2ea52cb4e9c07596cb63e484b310a0

[3] Seoul National University Hospital. Nationwide Study on the Prevalence of Dementia in Korean Elders. The report of Ministry for health, welfare and family affairs. 2008.

[4] Kim CM. The coping process of family caregivers for demented elderly at home. Seoul, Korea: Seoul National University; 2001.
[5] McCurry SM. When a family member has dementia: Steps to becoming a resilient caregiver. Westport: Praeger publishers; 2006.

[6] Chenoweth B, Spencer B. Dementia: The experience of family caregivers. Gerontologist. 1986; 26: 267-72. PMid:3721234 http: //dx.doi.org/10.1093/geront/26.3.267

[7] Walker AJ, Allen KR. Relationships between caregiving daughters and their elderly mothers. Gerontologist. 1991; 31: 389-96. PMid:1879715 http://dx.doi.org/10.1093/geront/31.3.3 89

[8] Kim SY, Kim JS, Youn HS. Predictors of Depression and Life Satisfaction among Family Caregivers for Demented Elderly. J Kor Geront Soc. $2004 ; 24: 111-28$

[9] Schulz R, O'Brien A, Bookwala J, et al. Psychiatric and physical morbidity effects of dementia caregiving: prevalence, correlated, and causes. Gerontologist. 1995; 35: 771-91. http://dx. doi .org/10. 1093/geront/35.6.771 
[10] Teri L, Logsddon RG, Uomoto J, et al. Behavioral treatment of depression in dementia patients: A controlled clinical trial. J Gerontol B Psychol Sci Soc Sci. 1997; 52: 159-66. http://dx.doi.org/1 $0.1093 /$ geronb/52B.4.P159

[11] Kiecolt-Glaser JK, Dura JR, Speicher CE, et al. Spousal caregivers of dementia victims: Longitudinal changes in immunity and health Psychosom Med. 1991; 53: 345-62. http://dx.doi .org/10.10 97/00006842-199107000-00001

[12] Miller B, Cafasso L. Gender differences in caregiving: Fact or artifact? Gerontologist. 1992; 32: 498-507. PMid:1427253 http: //dx.doi.org/10.1093/geront/32.4.498

[13] Lee SJ, Park HL, Kim NC. Life Satisfaction and Burden for Primary Caregivers of Patients with Dementia in Day Care Centers and in Their Homes. J Kor Gerontol Nurs. 2005; 7: 37-46.

[14] You KS. A study on the care burden of family caregivers for senile dementia. Journal of Korean Academy of Public Health Nursing. 2001; 15: 125-47.

[15] Schulz R, Martire LM. Family caregiving of persons with dementia: prevalece, health effects, and support strategies. Am J Geriatr Psychiatry. 2004; 12: 240-9. PMid:15126224 http://dx.doi .org/1 $0.1097 / 00019442-200405000-00002$

[16] Family caregiver alliance. Caregiver assessment: principles, guidelines and strategies for change. Report from a national consensus development conference. vol I. SanFrancisco, CA: Family caregiver alliance. 2006.

[17] Pearlin LI, Mulla JT, Semple SJ, et al. Caregining and the stress process: an overview of concepts and their measures. Gerontologist. 1990; 30: 583-94. http://dx.doi.org/10.1093/geront/30.5 .583

[18] Schulz R, Williamson GM. The measurement of caregiver outcomes in Alzheimer disease research. Alzheimer Dis Assoc Disord. 1997; 11: 117-24. PMid:9437456

[19] Oh H, Sok SH. Health Condition, Burden of Caring, and the Quality of Life among Family Members of the Elderly with Senile Dementia J Korean Acad Psychiatr Ment Health Nurs. 2009; 18: 157-66.

[20] Glaser R, Kiecolt-Glaser JK. Chronic stress modulates the virusspecific immune response to latent herpes simplex virus Type I. Ann Behav Med. 1997; 19: 78-82. http://dx.doi.org/10.1007/B F02883323

[21] Park AJ. A study on welfare services for family caregiver with senile dementia. Seoul, Korea: Korea University, Graduate School of Management and Information; 2001.

[22] Suh KH, Chun KI. The Moderate Effect of Social Support on Family Caregivers ' Burdens and Health and Quality of Life with Demented Patients. Kor J Psycho \& Soc Issues. 2009; 15: 339-57.

[23] Kennet J, Burgio L, Schulz R. Interventions for in-home caregivers: A review of research 1990 to present, in Handbook on Dementia Caregiving: Evidence-based interventions for family caregivers. Edited by Schulz R. New York: Springer; 2000. PMid:10755219

[24] Haley WE, Brown SL, Levine EG. Experimental evaluation of the effectiveness of group intervention for dementia caregivers. Gerontologist. 1987; 27: 376-82. http://dx.doi.org/10.1093/geront/ 27.3 .376

[25] Javadpour A, Ahmadzadeh L, Bahredar MJ. An educative support group for female family caregivers: Impact on caregivers psychological distress and patient's neuropsychiatry symptoms. Int J Geriatr Psychiatry. 2008; 24: 469-71. PMid:18937279 http://dx.doi.o $\mathrm{rg} / 10.1002 / \mathrm{gps} .2138$

[26] Kang JH. The effect of a social support program on burden and well-being in caregivers of elderly people with dementia living in the community. Seoul, Korea: Yonsei University; 2004.
[27] Dias A, Dewey ME, D'Souza J, et al. The effectiveness of a home care program for supporting caregivers of persons with dementia in developing countries: A randomized controlled trial from Goa, India. PLoS ONE. 2008; 3: e2333. PMid:18523642 http: //dx.doi.org/10.1371/journal.pone.0002333

[28] Seels B, Richey R. Instructional technology: The definition and domains of the field. Washington, DC: Association for Educational Communication and Technology. 1994.

[29] Cho YH. Family caregivers' needs for a professional help by the symptom level of senile dementia. Seoul, Korea: Yonsei University; 2007.

[30] Lynn MR. Determination and quantification of content validity. Nurs Res. 1986; 35: 382-6. PMid:3640358 http://dx.doi.org/10. 10 97/00006199-198611000-00017

[31] Canadian Study of Health and Aging Working Group. The incidence of dementia in Canada. The Canadian Study of Health and Aging Working Group. Neurology. 2000; 55: 66-73. PMid:10891908

[32] Chodosh J, Berry E, Lee M, et al. Effect of a dementia care management intervention on primary care provider knowledge, attitudes, and perceptions of quality of care. J Am Geriatr Soc. 2006; 54: 3117. PMid:16460384 http://dx.doi.org/10.1111/j.1532-541 $5.2005 .00564 . \mathrm{x}$

[33] Kuzu N, Beser N, Zencir M, et al. Effects of a comprehensive educational program on quality of life and emotional issues of dementia patient caregivers. Geriat Nurs. 2005; 26: 378-86. PMid:16373183 http://dx.doi.org/10.1016/j.gerinurse.2005.09.015

[34] Yoo EJ, Hah YS. Care need of the senile dementia patient's family. The Seoul Journal of Nursing. 1995; 9: 89-106.

[35] Joo KB. Constructing on primary caregiver's burn out model of the senile dementia elderly. Seoul, Korea: Kyunghee University; 2008.

[36] Chun KI. The caregivers' burden, physical and mental health with senile dementia patients using day care center. Seoul, Korea: Sahmyook University; 2008.

[37] Furlong KE, Wuest J. Self-care behaviors of spouses caring for significant others with Alzheimer's disease: The emergence of self-care worthiness as a salient condition. Qual Health Res. 2008; 18: 166272. PMid:19008361 http://dx.doi.org/10.1177/104973230 8327158

[38] Fortinsky RH, Kulldorff M, Kleppinger A, et al. Dementia care consultation for family caregivers: Collaborative model linking an Alzheimer's association chapter with primary care physicians. Aging Ment Health. 2009; 13: 162-70. PMid:19347683 http: //dx.doi.org/10.1080/13607860902746160

[39] Kim SY, Kim JW, Son SK, et al. The effectiveness of the group education program among the family caregivers of the demented elderly. Kor Welf Aged. 2007; 36: 7-34.

[40] Yoo EJ. The effect of group support program for the family caregivers of dementia patient. Seoul, Korea: Seoul National University; 2002.

[41] Chang BL. Cognitive-behavioral intervention for homebound caregivers of persons with dementia. Nurs Res. 1999; 48: 173-82. http://dx.doi.org/10.1097/00006199-199905000-00007

[42] Knight BG, Lutzky SM, Macofsky-Urban F. A meta-analytic review of interventions for caregiver distress: Recommendations for future research. Gerontologist. 1993; 33: 240-8. http://dx.doi.org/1 $0.1093 /$ geront/33.2.240

[43] Kuhlman GJ, Wilson HS, Hutchinson SA, et al. Alzheimer's disease and family caregiving: critical synthesis of the literature and research agenda. Nurs Res. 1991; 40: 331-7. http://dx.doi.org/10.10 97/00006199-199111000-00003 